\title{
HYBRID ZIPF-MANDELBROT LAW
}

\section{JULIJE JAKŠETIĆ, ĐILDA PEČARIĆ AND JOSIP PEČARIĆ}

Abstract. There is a unified approach, maximization of Shannon entropy, that naturally follows the path of generalization from Zipf's to hybrid Zipf's law. Extending this idea we make transition from Zipf-Mandelbrot to hybrid Zipf-Mandelbrot law. It is interesting that examination of its densities provides some new insights of Lerch's transcendent.

Mathematics subject classification (2010): 26D07, 26D15, 26D20, 26 D99.

Keywords and phrases: Shannon entropy, Zipf-Mandelbrot law, log-convex functions, Chebyshev's inequality, Lyapunov's inequality, Lerch's transcendent.

\section{REFERENCES}

[1] H. Bateman, A. ERdÉLyi, Higher Transcendental Functions Vol. I, New York: McGraw-Hill, 1953.

[2] E. T. JAYNES, Information theory and statistical mechanics, Phys. Rev. Ser. II 106 (1957), 620-630.

[3] E. T. JAYNES, Information theory and statistical mechanics: II, Phys. Rev. Ser. II 108 (1957), 171190.

[4] S. Frontier, Diversity and structure in aquatic ecosystems, Mar. Biol. Ann. Rev. 23(1985), $253-312$.

[5] J. JAKŠETIĆ, J. PEČARIĆ, Exponential Convexity method, J. Convex Anal., 20(1) (2013), 181-197.

[6] J. JAKŠETIĆ, Đ. PEČARIĆ, J. PEČARIĆ, Some properties of Zipf-Mandelbrot law and Hurwitz. $\zeta$-functionl, Math. Inequal. Appl., Accepted for publication

[7] B. Mandelbrot, An information theory of the statistical structure of language, In Jackson, W. (ed.), Communication Theory, New York, Academic Press, 1953.

[8] M. Matić, C. E. M. PEARCE, J. PEČARIĆ, Shannon's and related inequalities in information theory, In: Rassias, TM (ed.) Survey on Classical Inequalities, pp. 127-164. Kluwer Academic, Norwell (2000).

[9] J. PEČARIĆ, F. Proshan, Y. L. TOng, Convex functions partial ordering and statistical applications mathematics in Science and Engineering, Vol. 187., Academic Press, 1992.

[10] M. Visser, Zipf's law, power laws and maximum entropy, New J. Phys 15, 043021 (2013).

[11] G.K. ZIPF, Human Behavior and the Principle of Least Effort, Addison-Wesley, Reading, MA, 1949. 